\title{
Multiscale Coupling Framework for Modeling of Large-Size Biomass Particle Gasification in Fluidized Beds
}

\author{
Guodong Jin* \\ LNM, Institute of Mechanics, Chinese Academy of Sciences, Beijing 100190, P. R. China
}

\begin{abstract}
This paper is devoted to addressing a multiscale coupling framework for modeling of large-size biomass particle gasification in fluidized beds, where the large diffusions due to the temperature and concentration gradients in large-size particles strongly affect gasification process. Directly incorporating a single particle model (SPM) into a conventional fluidized-bed model tremendously increases the computational cost. In this paper, we propose a loose coupling framework between the SPM and the discrete element method (DEM)-Eulerian continuum model. The SPM is based on detailed reaction mechanisms and has been validated against experimental results. The rationality of the coupling is based on the observations from the SPM that the temperature is the dominating factor and the surrounding gas velocity is a secondary one to the gasification. For this purpose, we use sand particles as thermal carrier to keep the surrounding temperature statistically stable. We then simulated the gasification of beech wood particles mixed with sand particles in a bubbling fluidized bed. The entrainment and mixing of wood particles with sand particles can be observed and the particle distribution and the composition of gas phase can be obtained. The proposed method provides a potential way to account for the gasification process of large-size biomass particles in fluidized beds.
\end{abstract}

\section{INTRODUCTION}

Biomass has been regarded as a clean and renewable energy source. ${ }^{1,2}$ One of the clean and high efficient utilization methods of biomass is gasification, which is a thermochemical conversion process of macromolecular biomass particles into syngas mainly with $\mathrm{CO}, \mathrm{CH}_{4}$, and $\mathrm{H}_{2}$, and so on. It occurs with an understoichiometric supply of oxygen to maintain an autothermic operation, and it includes several subprocesses of drying, primary pyrolysis, secondary pyrolysis of tar, and many homogeneous reactions and heterogeneous reactions, where the pyrolysis is a key step. ${ }^{3}$

Gasification models of biomass particles, such as wood particles may be classified into small-size particle model and large-size particle model (or microparticle and macroparticle models). In small-size particle model, it is assumed that the particle is isothermal and the diffusion effects can be neglected. The gasification process is kinetically controlled. The critical particle size estimate for kinetic control is about $0.1-1 \mathrm{~mm}$. Oevermann et al. ${ }^{5}$ performed an Eulerian-Lagrangian simulation of wood gasification in a bubbling fluidized bed using a microparticle model. The gasification process of large-size particles with the temperature and concentration gradients along the particle radius is determined by the kinetics, the diffusion effects, and the flow boundary layer surrounding the particle, and so on.

As grinding of biomass materials into small size particles is economically unfeasible, since extra energy required for grinding, thus large-size particles are usually encountered in practical applications. For an example, wood particle diameter could be as large as $6.35 \mathrm{~mm}$ for gasification. ${ }^{6}$ Miller and Bellan have developed a single particle model (SPM) to describe the pyrolysis of large-size particles. ${ }^{4}$ Okekunle et al. have numerically and experimentally studied the effects of biomass size and aspect ratio on intraparticle decomposition during pyrolysis of wood cylinder based on a 2D, unsteady SPM to account for the different thermal conductivity coefficients along a grain and radial directions.

Fluidized beds are usually used as a gasifier because of the high efficiency. The gas-particle two-phase thermochemical flows in the fluidized bed manifest their complexity with multiscale heterogeneous structures such as the bubbles or particle clusters. ${ }^{8}$ Many efforts have been devoted to modeling the multiscale structures in fluidized beds. Among others, the energy-minimization multiscale (EMMS) method has been proposed ${ }^{9}$ and recently extended to the subgrid level to account for the mesoscale clusters in the numerical simulation of fluidized beds. ${ }^{10-13}$

The gasification of a large-size biomass particle in a fluidized bed involves several orders of scales, ranging from $10^{-9} \mathrm{~m}$ at the atomistic scale to $1 \mathrm{~m}$ at the reactor scale: (1) the pyrolysis, the homogeneous and heterogeneous reactions occur at the molecular level; (2) the diffusions occur at the subparticle level because of the temperature and gas concentration gradients; (3) the momentum, mass and energy exchange between the wood particle surface, and the gas phase at the particle scale; 4) the heterogeneous flow structures such as bubbles or clusters at the mesoscale; and 5) the core-annular flow structures at the reactor scale. Multiscale/multiphysics modeling is essential for such a complex particle-fluid two-phase system with chemical reactions. ${ }^{14}$ The resolution of the system into different subscales and coupling between them are the two essential characteristics of the multiscale problems. ${ }^{9,15}$ Pannala et al ${ }^{14}$ proposed a time parallel compound wavelet matrix (tpCWM)

Special Issue: Multiscale Structures and Systems in Process Engineering

Received: February 4, 2013

Revised: $\quad$ May 21, 2013

Accepted: May 21, 2013

Published: May 21, 2013 
method for coupling multiscale/multiphysics components in biomass thermochemical process.

In a recent review article, Di Blasi has pointed out that "simplified descriptions of single particle pyrolysis accounting for spatial gradients of temperature, once incorporated in reactor models, could produce a significant advancement with respect to the current state of the art" ${ }^{16}$ For this purpose, Anca-Couce and Zobel $^{17}$ and Anca-Couce et al. ${ }^{18}$ have incorporated a representative particle model for pyrolysis of wood particle into a fixed bed model.

The objective of this paper is to propose a framework for the multiscale method for the gasification of large-size particle in a fluidized bed by coupling the SPM into conventional fluidized bed model. The question of the research is to build a loose coupling method on the basis of the characteristic of gasification of wood particles. The basic idea is to couple a database of the gasification process of a large-size biomass particle under given surrounding conditions with the discrete element method (DEM)-continuum model. The database at particle scale is obtained by solving the SPM which has been validated against experimental results. ${ }^{3}$ The DEM-continuum method is used to describe the dynamics of particles and gas flows in the fluidized bed.

The structure of the paper is organized as follows: the overall setup of the multiscale coupling framework is introduced in section 2 with subsections to account for the kinetics of biomass gasification, the SPM, the DEM for the dynamic of particles, and the Eulerian gas flow governing equations; the computational modeling results and discussions are presented in section 3 , and the conclusions are given in section 4 .

\section{PROPOSED MULTISCALE COUPLING FRAMEWORK}

2.1. Structure of the Multiscale Coupling Framework. A typical gasification of biomass particle undergoes heating, drying, pyrolysis, secondary pyrolysis of tar, and homogeneous and heterogeneous reactions, it occurs across several scales. We use different models to describe the subprocesses at different scales. Figure 1 shows the coupling framework among the

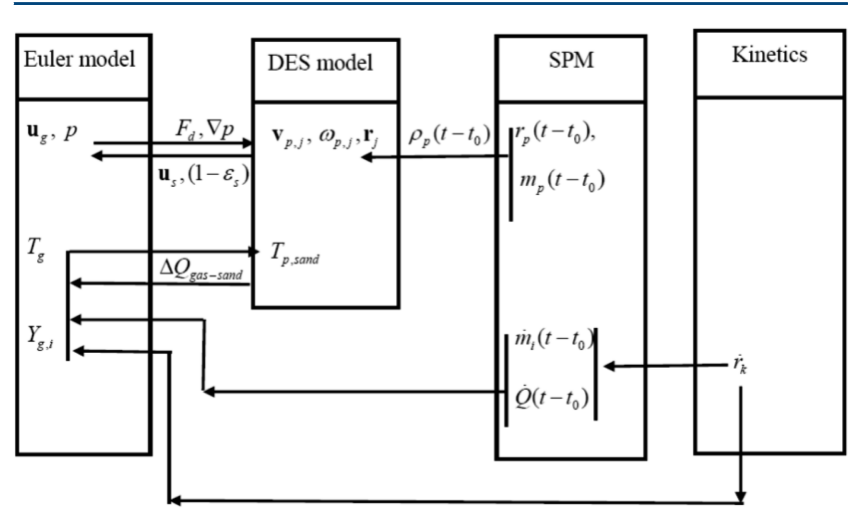

Figure 1. Coupling method among models at different scales.

models at different scales. From the Eulerian model for the gas phase, we get gas velocity, pressure, temperature, and gas species, $\mathbf{u}_{\mathrm{g}}, p, T_{\mathrm{g}}, Y_{\mathrm{g}, i}$. From the DEM model, we can get the velocity, angular velocity, and position of particle $i, \mathbf{v}_{\mathrm{p}, i}, \omega_{\mathrm{p}, i}, \mathbf{r}_{i}$; we can also get the temperature of the sand particles $T_{\mathrm{p}, \text { sand, } i}$. The Eulerian model and the DEM model are coupled through the drag force, pressure difference force and the heat transfer between the particles and the gas phase, $F_{\mathrm{d}}, \nabla p$, and $\Delta Q_{\text {gas-sand. }}$.
From the results of the DEM, we can get the particle volume fraction and solid phase velocity $\varepsilon_{s}, \mathbf{u}_{\mathrm{s}}$ by grid averaging. With the SPM solved under typical boundary and initial conditions, we can get the temporal variation of the radius and averaged mass of wood particles $r_{\mathrm{p}}\left(t-t_{0}\right), m_{\mathrm{p}}\left(t-t_{0}\right)$, then we can get the biomass particle density $\rho_{\mathrm{p}}\left(t-t_{0}\right)$ for the DEM calculation. We can also get the mass and heat fluxes from biomass particle $\dot{m}_{i}\left(t-t_{0}\right), \dot{Q}\left(t-t_{0}\right)$ for Eulerian model calculation, where $t_{0}$ is the time at which a biomass particle goes into the fluidized bed. From the kinetics model, we can calculate the chemical reactions in the SPM and in the homogeneous reactions in gas phase within the particle and in the fluidized bed.

The DEM-Eulerian model is solved using the multiphase reacting flow software MFIX (multiphase flow with interphase exchanges, http://mix.netl.doe.gov/), and the coupling the DEM-Eulerian model and database of SPM is implemented using its user subroutines. ${ }^{19}$

2.2. Drying. Biomass usually contains about $40-100 \% \mathrm{db}$ (dry basis) of water. An accurate modeling of drying is essential for gasification. The particle size, initial moisture content, temperature, and relative humidity affect the drying process. The liquid (free and absorbed water) is assumed to be in equilibrium with the local gas phase in pores. A drying rate (or evaporation rate) can be expressed as ${ }^{20}$

$$
\dot{r}_{\text {dry }}=-k_{0} \varphi_{\mathrm{pg}}\left(\frac{p_{\mathrm{p}, \mathrm{H}_{2} \mathrm{O}}^{*}}{R T_{\mathrm{par}}}-\frac{Y_{\mathrm{g}, \mathrm{H}_{2} \mathrm{O}} \rho_{\mathrm{pg}}}{M_{\mathrm{H}_{2} \mathrm{O}}}\right)
$$

In this paper, the drying process is neglected for simplicity, that is, the dry wood particles are gasified in this study.

2.3. Pyrolysis Model. The pyrolysis process is the nonoxidative decomposition of biomass in the absence of oxidizing agents at high temperature, resulting in many chemical products. The process is composed of the primary and the second pyrolysis. In the primary pyrolysis, the products include permanent gases such as $\mathrm{CO}, \mathrm{CO}_{2}, \mathrm{CH}_{4}, \mathrm{H}_{2}$ and $\mathrm{H}_{2} \mathrm{O}$, condensed vapors of high molecular weight hydrocarbons ( $\operatorname{tar}$ ) and residual carbon (char). In the second pyrolysis, the tar is further decomposed into gas and char. Biomass pyrolysis is a key step for the gasification of biomass particles and many types of models have been developed for biomass pyrolysis. For complete reviews of related work, please refer to ref 16 . Miller and Bellan have used an irreversible and first order Arrhenius reaction to model biomass pyrolysis model based on superimposed cellulose, hemicellulose, and lignin kinetics. ${ }^{4}$ In this study, the pyrolysis model of independent parallel reaction is used and the primary pyrolysis can be described by

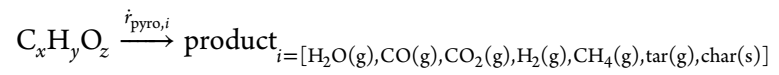

where $\dot{r}_{\text {pyro,j }}$ denotes the pyrolysis rate of the individual product, $\dot{r}_{\mathrm{pyro}, i}=k_{0 i} \exp \left(-E_{i} / R T_{\mathrm{par}}\right) Y_{\mathrm{ps}, i} \rho_{\mathrm{ps}} \varphi_{\mathrm{ps}}$ and $Y_{\mathrm{ps}, i} \rho_{\mathrm{ps}} \varphi_{\mathrm{ps}}$ is the amount of not volatilized pyrolysis gas left in the solid phase. The kinetic parameters used in this paper are shown in Table 1, where parameters are taken from the thermogravimetric (TGA) experiment with $1 \mathrm{~mm}$ particles under atmospheric conditions; at heating rate of $5 \mathrm{~K} / \mathrm{min}$ and a maximum temperature of $1173 \mathrm{~K}^{21}$ We take the beech wood particles with diameter of 1 $\mathrm{mm}$ as example in the paper. The values in the last column of Table 1 denote the maximum of different pyrolysis gases and tar. Initially, the wood particles are represented by these 
Table 1. Primary Pryolysis Kinetics of Beech

\begin{tabular}{lccc} 
component & $K_{0 i}(1 / \mathrm{s})$ & $E(\mathrm{~kJ} / \mathrm{mol})$ & $Y_{\mathrm{ps}, j}$ \\
$\mathrm{H}_{2} \mathrm{O}$ & $3.68 \times 10^{13}$ & 149.5 & 0.0480 \\
$\mathrm{CO}$ & $9.00 \times 10^{9}$ & 111.0 & 0.0506 \\
$\mathrm{CO}_{2}$ & $5.23 \times 10^{9}$ & 105.0 & 0.0724 \\
$\mathrm{H}_{2}$ & $4.73 \times 10^{4}$ & 92.5 & 0.0060 \\
$\mathrm{CH}_{4}$ & $1.09 \times 10^{5}$ & 71.3 & 0.0106 \\
$\operatorname{Tar}(\mathrm{g})$ & $2.09 \times 10^{10}$ & 112.7 & 0.6340 \\
\hline
\end{tabular}

maximum yield values of different gases and char, which adds up to $17.8 \%$.

The secondary pyrolysis follows the primary one and it is the cracking of tar in which high molecular hydrocarbons are decomposed into low molecular hydrocarbons,

$$
\begin{aligned}
\alpha_{\mathrm{tar}} \operatorname{tar} \rightarrow & \alpha_{\mathrm{CO}} \mathrm{CO}(\mathrm{g})+\alpha_{\mathrm{CO}_{2}} \mathrm{CO}_{2}(\mathrm{~g})+\alpha_{\mathrm{CH}_{4}} \mathrm{CH}_{4}(\mathrm{~g}) \\
& +\alpha_{\mathrm{H}_{2}} \mathrm{H}_{2}(\mathrm{~g})
\end{aligned}
$$

where $\alpha_{i}$ is the relative stoichiometric coefficients of each cracked species and is given in Table $2 .{ }^{22}$ For the reaction rate,

Table 2. Relative Yields of Tar Cracking Products

\begin{tabular}{cc} 
component & $\alpha$ \\
Tar & -1 \\
$\mathrm{CO}$ & 0.72222 \\
$\mathrm{H}_{2}$ & 0.02222 \\
$\mathrm{CO}_{2}$ & 0.14222 \\
$\mathrm{CH}_{4}$ & 0.11334 \\
\hline
\end{tabular}

the kinetic model, $\dot{r}_{i, \text { crack }}=\alpha_{i} \times 10^{4.98} \exp \left(-93.37 / R T_{\text {par }}\right)$ $Y_{\mathrm{pg}, \mathrm{tar}} \rho_{\mathrm{pg}} \varphi_{\mathrm{pg}}$ is used, where $Y_{\mathrm{pg}, \mathrm{tar}} \rho_{\mathrm{pg}} \varphi_{\mathrm{pg}}$ denotes the amount of tar in the gas phase in the wood particle.

2.4. Homogeneous Gas Phase Reactions. Reactive gas species are produced during drying and pyrolysis of biomass and they react with each other. For simplicity, the following four homogeneous reactions are considered in this study.

$$
\begin{aligned}
& \mathrm{CO}+\mathrm{H}_{2} \mathrm{O} \stackrel{\text { hom } 1}{\longleftrightarrow} \mathrm{CO}_{2}+\mathrm{H}_{2} \\
& 2 \mathrm{CO}+\mathrm{O}_{2} \stackrel{\text { hom } 2}{\longrightarrow} 2 \mathrm{CO}_{2} \\
& 2 \mathrm{H}_{2}+\mathrm{O}_{2} \stackrel{\text { hom } 3}{\longrightarrow} 2 \mathrm{H}_{2} \mathrm{O} \\
& \mathrm{CH}_{4}+2 \mathrm{O}_{2} \stackrel{\text { hom } 4}{\longrightarrow} \mathrm{CO}_{2}+2 \mathrm{H}_{2} \mathrm{O}
\end{aligned}
$$

where eq 4 is equilibrium limited reaction. At lower temperatures, it favors the production of $\mathrm{CO}_{2}$ and $\mathrm{H}_{2}$, and at higher temperatures $\mathrm{CO}$ and $\mathrm{H}_{2} \mathrm{O}$ with an equilibrium constant depending on the gas temperature. ${ }^{23}$ Here we assume that the gas temperature in the particle is the same as the particle local temperature $T_{\text {par }}$. The oxidation rate of $\mathrm{CO}$ in eq 4 depends on the concentrations of moisture $\left(\mathrm{H}_{2} \mathrm{O}(\mathrm{g})\right), \mathrm{O}_{2}$, and $\mathrm{CO}^{24}$ The kinetic parameters are taken from literature and listed in Table 3.

The standard enthalpy changes of the above homogeneous reactions at $T_{\text {ref }}=298.15 \mathrm{~K}$ and $p_{\text {ref }}=100000 \mathrm{~Pa}$ are listed in Table 4.

Table 4. Heat of Reaction in Different Homogeneous Gas Phase Reactions

$\begin{array}{lc}\text { reaction } & \text { value }(\mathrm{kJ} / \mathrm{mol}) \\ \Delta h_{\text {hom } 1} & -41.137 \\ \Delta h_{\text {hom2 }} & -565.986 \\ \Delta \mathrm{ih}_{\text {hom } 3} & -483.712 \\ \Delta h_{\text {hom } 4} & -802.361\end{array}$

2.5. Heterogeneous Reaction. Heterogeneous reactions occur between solid char (pyrolysis residue) and species in the gas phase (such as $\mathrm{O}_{2}, \mathrm{CO}_{2}$, and $\mathrm{H}_{2} \mathrm{O}$ ). ${ }^{27}$ The simplified reaction model consists of the following overall reactions:

$$
\begin{aligned}
& 2 \frac{\eta+1}{\eta+2} \mathrm{C}+\mathrm{O}_{2} \stackrel{\text { het1 }}{\longrightarrow} \frac{2 \eta}{\eta+2} \mathrm{CO}+\frac{2}{\eta+2} \mathrm{CO}_{2} \\
& \mathrm{C}+\mathrm{CO}_{2} \stackrel{\text { het2 }}{\longrightarrow} 2 \mathrm{CO} \\
& \mathrm{C}+\mathrm{H}_{2} \mathrm{O} \stackrel{\text { het3 }}{\longrightarrow} \mathrm{CO}+\mathrm{H}_{2}
\end{aligned}
$$

where $\eta$ is the production ratio of $\mathrm{CO} / \mathrm{CO}_{2}$. It changes with temperatures $\eta=750 \exp \left(-7200 / T_{\mathrm{p}}\right){ }^{24}$ The rates of these heterogeneous reactions are taken from literature and listed in Table 5.

The standard enthalpy changes of the above heterogeneous reactions are listed in Table 6.

2.6. Single Particle Model (SPM). Wilmes ${ }^{3}$ has thoroughly studied the SPM based on detailed reaction mechanism. The model is numerical solved and validated against the experimental results. Good agreement between the numerical and experimental results was obtained. For completeness, we shall briefly describe the model. For more details, please refer to ref 3 . In the SPM, the large-size biomass

Table 3. Rate Expressions for Homogeneous Gas-Phase Reactions

$$
\begin{aligned}
& \text { De Souza-Santos }{ }^{25} \\
& \dot{r}_{\text {hom } 1}=2.78 \exp \left(\frac{-1513}{T_{\mathrm{g}}}\right)\left(C_{\mathrm{CO}} C_{\mathrm{H}_{2} \mathrm{O}}-\frac{C_{\mathrm{CO}} C_{\mathrm{H}_{2} \mathrm{O}}}{K_{\mathrm{e}}}\right) \mathrm{mol} /\left(\mathrm{m}^{3} \cdot \mathrm{s}\right) \\
& \text { Yoon et al. }{ }^{23} \\
& K_{\mathrm{e}}=0.0265 \exp \left(3966 / T_{\mathrm{g}}\right) \\
& \text { Cooper and Hallet }{ }^{24} \\
& \dot{\text { rhom } 2}_{\text {in }}=1.3 \times 10^{14} \exp \left(\frac{-15105}{T_{\mathrm{g}}}\right) C_{\mathrm{CO}} C_{\mathrm{O}_{2}} C_{\mathrm{H}_{2} \mathrm{O}}^{0.5} \mathrm{~mol} /\left(\mathrm{m}^{3} \cdot \mathrm{s}\right) \\
& \text { Di Blasi }{ }^{26} \\
& \dot{r}_{\text {hom } 3}=10^{14} \exp \left(\frac{-10000}{T_{g}}\right) C_{\mathrm{H}_{2}} C_{\mathrm{O}_{2}} \mathrm{~mol} /\left(\mathrm{m}^{3} \cdot \mathrm{s}\right) \\
& \text { Di Blasi }{ }^{26} \\
& \dot{r}_{\text {hom } 4}=1.58 \times 10^{13} \exp \left(\frac{-24343}{T_{\mathrm{g}}}\right) C_{\mathrm{CH}_{4}}^{0.7} C_{\mathrm{O}_{2}}^{0.8} \mathrm{~mol} /\left(\mathrm{m}^{3} \cdot \mathrm{s}\right)
\end{aligned}
$$


Table 5. Heat of Reaction in Different Heterogeneous Reactions

$$
\begin{array}{ll}
\text { Di Blasi et al. }{ }^{28} & \dot{r}_{\text {het1 }}=1.5 \times 10^{6} \exp \left(\frac{-13078}{T_{\text {par }}}\right) p_{\mathrm{O}_{2}}\left(1-x_{\mathrm{c}}\right)^{1.2}(1 / \mathrm{s}) \\
\text { Biggs and Agarwal }^{29} & \dot{r}_{\text {het2 }}=4364 \exp \left(\frac{-29844}{T_{\text {par }}}\right) C_{\mathrm{CO}_{2}}(\mathrm{~mol} / \mathrm{m} 2 / \mathrm{s}) \\
\text { Mühlen et al. }^{30} & \dot{r}_{\text {het3 }}=\frac{a_{1} p_{\mathrm{H}_{2} \mathrm{O}}}{1+a_{2} p_{\mathrm{H}_{2} \mathrm{O}}+a_{3} p_{\mathrm{H}_{2}}}(1 / \mathrm{s}) \\
a_{1} & =4.93 \times 10^{3} \exp \left(-18522 / T_{\text {par }}\right)(1 / \mathrm{bar} / \mathrm{s}) \\
a_{2} & =1.11 \times 10^{1} \exp \left(-3548 / T_{\text {par }}\right)(1 / \mathrm{bar}) \\
a_{3} & =1.53 \times 10^{-9} \exp \left(25161 / T_{\text {par }}\right)(1 / \mathrm{bar})
\end{array}
$$

Table 6. Heat of Reaction in Different Heterogeneous Reactions in Eqs 8-10

\begin{tabular}{cl} 
reaction & \multicolumn{1}{c}{ value $(\mathrm{kJ} / \mathrm{mol})$} \\
$\Delta h_{\text {het1 }}$ & $-(221.056 \eta+87.042) /(\eta+2)$ \\
$\Delta h_{\text {het2 }}$ & 172.565 \\
$\Delta h_{\text {het3 }}$ & 131.328
\end{tabular}

wood particle is regarded as a porous mixture consisting of solid matrix, liquid water and gas phases, as shown in Figure 2.

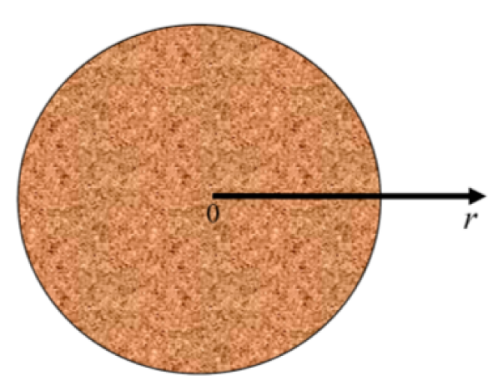

Figure 2. Sketch map of a large-size biomass particle. The particle is assumed to be spherically symmetric, and 0 denotes the center of the particle, while $r$ is the spherical coordinator.

A set of governing equations, such as overall mass continuity equations, species mass continuity equations, momentum equations, and total energy equation, together with a series of chemical reactions introduced in the previous subsections are used to describe the gasification process in the large-size particle and listed in Table 7 . The following assumptions are used in the model: (1) the wood particle is spherically symmetric, thus $\partial / \partial \theta=\partial / \partial \varphi=0$; (2) phases are in thermal equilibrium; (3) Darcy's law is valid for gas and liquid water in the porous media; (4) liquid is in local equilibrium with gas phase; and (5) the state equation of ideal gas is valid for the gas phase.

Equations 11-17 with initial and boundary conditions are solved using the LIMEX software. Details about the initial and boundary conditions and the parameters for wood particle, please refer to ref 3. The solutions to the SPM were validated against experimental results and the numerical results agree well with the experimental results. Once the solutions at the particle boundary are obtained, we can integrate the solutions at the particle surface with the DEM-continuum model. The numerical results under different conditions such as bulk gas velocities and surrounding temperatures will be discussed in section 4 .

2.7. Discrete Element Method (DEM). For large-size biomass particle, the radius of wood particles changes with time, thus the Lagrangian method is used to track the trajectories of particles in this study. DEM is a Lagrangian approach, tracking the trajectory of the individual particle by integrating the motion of equation of each particle according to the second Newtonian law. The collisions between particles are described using the soft-particle model. One particle can simultaneously contact several neighboring particles over a certain period. This method was first proposed by Cundall and Strack $^{31}$ for granular flow and then was extended by Tusji et al. ${ }^{32}$ to simulate the gas-solid flow in fluidized beds.

2.7.1. Translational and Rotational Motion Equations for Particles. The forces acting on the particle $i$ are gravity force $m_{\mathrm{p}, \mathrm{g}} \mathbf{g}$, pressure difference force $-V_{\mathrm{p}} \nabla \mathrm{p}$, gas drag force $\mathbf{F}_{\mathrm{d}}$ and particle contacting force $\mathbf{F}_{c, i}$ during collision. The torque caused by the tangential component of contacting force, $\mathbf{F}_{\mathrm{ct}, i}$ is $\mathbf{T}_{\mathrm{c}, i}$. Normal force at the contact point is modeled using the massspring-dashpot model. The tangential contacting force at the contact point is modeled using the mass-spring (slider)-dashpot model. The details about the DEM model please refer to ref 32. One additional assumption in this paper is that the same parameters for the spring stiffness and damping coefficient are used to treat the interaction between the sand and biomass particles for simplicity. The translational and rotational accelerations of particle $i$ are

$$
\begin{aligned}
& \boldsymbol{\alpha}_{\mathrm{p}, i}=\frac{\mathrm{d} \mathbf{v}_{\mathrm{p}, i}}{\mathrm{~d} t}=\mathbf{g}-\frac{V_{\mathrm{p}, i}}{m_{\mathrm{p}, i}} \nabla p+\frac{\mathbf{F}_{\mathrm{d}, i}}{m_{\mathrm{p}, i}}+\frac{1}{m_{\mathrm{p}, i}} \mathbf{F}_{\mathrm{c}, i} \\
& \dot{\boldsymbol{\omega}}_{\mathrm{p}, i}=\frac{\mathrm{d}}{\mathrm{d} t} \boldsymbol{\omega}_{\mathrm{p}, i}=\frac{1}{I_{i}} \mathbf{T}_{\mathrm{c} i}\left(I_{i}=\frac{1}{10} m_{\mathrm{p}, i} d_{\mathrm{p}, i}^{2}\right)
\end{aligned}
$$

Integrating the above equations with respect to time, one can get the translational velocity, rotational velocity, and the position.

2.7.2. Total Force and Torque. In dense gas-solid flows, particle $i$ can contact several other particles at the same time, the total force and torque acting on particle $i$ can be obtained by summing up with respect to neighboring particles $j$

$$
\begin{aligned}
& \mathbf{F}_{\mathrm{c}, i}=\sum_{j}\left(\mathbf{F}_{\mathrm{ct}, i j}+\mathbf{F}_{\mathrm{cn}, i j}\right) \\
& \mathbf{T}_{\mathrm{c}, i}=\sum_{j}\left(r_{i} \mathbf{n}_{i j} \times \mathbf{F}_{\mathrm{ct}, i j}\right)
\end{aligned}
$$

2.7.3. Solid-Phase Velocity and Volume Fraction. The solid phase Eulerian velocity and volume fraction can be obtained by averaging all the particles in a control volume (or computational cell). Assuming there are $n$ particles at a computational cell at time $t$, then the volume of particle $i$ is $V_{\mathrm{p}, i}=\pi d_{\mathrm{p}, \mathrm{s}}^{3} / 6$, then the solid volume fraction and solid phase velocity are

$$
\begin{aligned}
& \varepsilon_{\mathrm{s}}(x, t)=\sum_{i=1}^{n} V_{\mathrm{p}, i} / \Delta x \Delta y d_{\mathrm{p}, \mathrm{s}} \\
& \mathbf{u}_{\mathrm{s}}(x, t)=\sum_{i=1}^{n} \mathbf{v}_{\mathrm{p}, i} V_{\mathrm{p}, i} \rho_{\mathrm{p}, i} / \sum_{i=1}^{n} V_{\mathrm{p}, i} \rho_{\mathrm{p}, i}
\end{aligned}
$$

where the grid size in the $z$ direction is set to be one sand particle diameter $d_{\mathrm{p}, \mathrm{s}}$. 
Table 7. Governing Equations of the SPM

$$
\begin{aligned}
& \text { mass continuity } \\
& \text { gas } \\
& \frac{\partial \varphi_{\mathrm{pg}} \rho_{\mathrm{pg}}}{\partial t}=\frac{1}{r^{2}} \frac{\partial}{\partial r}\left(r^{2} \rho_{\mathrm{pg}} \frac{K_{\mathrm{g}}}{\mu_{\mathrm{g}}} \frac{\partial p_{\mathrm{pg}}}{\partial r}\right)+r_{\mathrm{s} \rightarrow \mathrm{g}}+r_{\mathrm{l} \rightarrow \mathrm{g}} \\
& \text { liquid } \\
& \frac{\partial \varphi_{\mathrm{p}} \rho_{\mathrm{pl}}}{\partial t}=\frac{1}{r^{2}} \frac{\partial}{\partial r}\left[r^{2}\left(\rho_{\mathrm{pl}} \frac{K_{\mathrm{l}}}{\mu_{\mathrm{l}}} \frac{\partial\left(p_{\mathrm{pg}}-p_{\mathrm{c}}\right)}{\partial r}+D_{\mathrm{b}} \frac{\partial \rho_{\mathrm{pl}}}{\partial r}\right)\right]-r_{\mathrm{l} \rightarrow \mathrm{g}} \\
& \text { solid } \\
& \frac{\partial \varphi_{\mathrm{ps}} \rho_{\mathrm{ps}}}{\partial t}=-r_{\mathrm{s} \rightarrow \mathrm{g}} \\
& \text { state equation } \\
& \text { gas } \\
& \rho_{\mathrm{pg}}=p_{\mathrm{pg}} \bar{M} / R T_{\mathrm{par}} \\
& \frac{\partial \varphi_{\mathrm{pg}} \rho_{\mathrm{pg}} Y_{\mathrm{pg}, i}}{\partial t}=\frac{1}{r^{2}} \frac{\partial}{\partial r}\left[r^{2}\left(\rho_{\mathrm{pg}} Y_{\mathrm{pg}, i} \frac{K_{\mathrm{g}}}{\mu_{\mathrm{g}}} \frac{\partial p_{\mathrm{pg}}}{\partial r}+\rho_{\mathrm{pg}} Y_{\mathrm{pg}, i} D_{\mathrm{eff}, i} \frac{1}{X_{\mathrm{pg}, i}} \frac{\partial X_{\mathrm{pg}, i}}{\partial r}\right)\right]+r_{\mathrm{g} \rightarrow \mathrm{g}, i} \\
& \text { species equation } \\
& \text { gas } \\
& +r_{\mathrm{s} \rightarrow \mathrm{g}, i}+r_{\mathrm{l} \rightarrow \mathrm{g}, i} \\
& \frac{\partial \varphi_{\mathrm{ps}} \rho_{\mathrm{ps}} Y_{\mathrm{ps}, i}}{\partial t}=r_{\mathrm{s} \rightarrow \mathrm{s}, \mathrm{char}}-r_{\mathrm{s} \rightarrow \mathrm{g}, i} \\
& {\left[\varphi_{\mathrm{pg}} \rho_{\mathrm{pg}} C_{\mathrm{pg}}+\varphi_{\mathrm{pl}} \rho_{\mathrm{pl}} C_{\mathrm{pl}}+\left(1-\varphi_{\mathrm{pg}}-\varphi_{\mathrm{pl}}\right) \rho_{\mathrm{ps}} C_{\mathrm{ps}}\right] \frac{\partial T_{\mathrm{par}}}{\partial t}} \\
& =\left(\rho_{\mathrm{pg}} C_{\mathrm{pg}} \frac{K_{\mathrm{g}}}{\mu_{\mathrm{g}}} \frac{\partial p_{\mathrm{pg}}}{\partial r}+\rho_{\mathrm{pl}} C_{\mathrm{pl}} \frac{K_{\mathrm{l}}}{\mu_{1}} \frac{\partial\left(p_{\mathrm{pg}}-p_{\mathrm{c}}\right)}{\partial r}\right) \frac{\partial T_{\mathrm{par}}}{\partial r} \\
& -\left(\sum_{i} C_{\mathrm{p} g, i} D_{\mathrm{eff}, i} \frac{Y_{\mathrm{pg}, i}}{X_{\mathrm{pg}, i}} \frac{\partial X_{\mathrm{pg}, i}}{\partial r}+C_{\mathrm{pl}} D_{\mathrm{b}} \frac{\partial \rho_{\mathrm{pl}}}{\partial r}\right) \frac{\partial T_{\mathrm{par}}}{\partial r}+\frac{1}{r^{2}} \frac{\partial}{\partial r}\left(r^{2} \lambda_{\mathrm{eff}} \frac{\partial T_{\mathrm{par}}}{\partial r}\right)-Q
\end{aligned}
$$

\section{Table 8. Governing Equations of the Gas Phase}

$$
\begin{array}{ll}
\text { mass continuity } & \frac{\partial}{\partial t}\left(\varepsilon_{\mathrm{g}} \rho_{\mathrm{g}}\right)+\nabla \cdot\left(\varepsilon_{\mathrm{g}} \rho_{\mathrm{g}} \mathbf{u}_{\mathrm{g}}\right)=\sum_{i=1}^{N_{\mathrm{g}}} \dot{R}_{\mathrm{g}, i} \\
\text { species equation } & \frac{\partial}{\partial t}\left(\varepsilon_{\mathrm{g}} \rho_{\mathrm{g}, i}\right)+\nabla \cdot\left(\varepsilon_{\mathrm{g}} \rho_{\mathrm{g}, i} \mathbf{u}_{\mathrm{g}}\right)=\nabla \cdot\left(D_{\mathrm{g}, i} \nabla Y_{\mathrm{g}, i}\right)+\dot{R}_{\mathrm{g}, i} \\
\text { momentum equation } & \frac{\partial}{\partial t}\left(\varepsilon_{\mathrm{g}} \rho_{\mathrm{g}} \mathbf{u}_{\mathrm{g}}\right)+\nabla \cdot\left(\varepsilon_{\mathrm{g}} \rho_{\mathrm{g}} \mathbf{u}_{\mathrm{g}} \mathbf{u}_{\mathrm{g}}\right)=-\varepsilon_{\mathrm{g}} \nabla p+\nabla \cdot \varepsilon_{\mathrm{g}} \overline{\bar{\tau}}_{\mathrm{g}}+\varepsilon_{\mathrm{g}} \rho_{\mathrm{g}} \mathbf{g}-\beta_{\mathrm{g}-\mathrm{s}}\left(\mathbf{u}_{\mathrm{g}}-\mathbf{u}_{\mathrm{s}}\right) \\
\text { energy equation } & \varepsilon_{\mathrm{g}} \rho_{\mathrm{g}} \mathrm{g}_{\mathrm{g}}\left(\frac{\partial}{\partial t} T_{\mathrm{g}}+\mathbf{u}_{\mathrm{g}} \cdot \nabla T_{\mathrm{g}}\right)=-\nabla \cdot \mathbf{q}_{\mathrm{g}}+\dot{Q}_{\text {sand }-\mathrm{gas}}+\dot{Q}_{\text {wood }-\mathrm{gas}}-\Delta H_{\mathrm{rg}} \\
\text { state equation } & \rho_{\mathrm{g}}\left(T_{\mathrm{g}}\right)=\frac{p_{\mathrm{g}} \bar{M}}{R T_{\mathrm{g}}}=p_{\mathrm{g}} / R T_{\mathrm{g}} \sum_{i=1}^{N} \frac{X_{\mathrm{g}, i}}{M_{\mathrm{g}, i}}
\end{array}
$$

2.7.4. Energy Equation for Sand Particle. In this study, sand particles are used as heat carrier. Assumed that the temperature of sand particle is homogeneous, the change rate of the temperature of sand particle $i$ from convection, $Q_{\mathcal{O}}$ from thermal radiation, $Q_{r}$, and from the energy exchange during collision $Q_{\text {coll }}$ is

$$
m_{\mathrm{p}, i} C_{\mathrm{p}, \text { sand }} \frac{\mathrm{d} T_{\mathrm{p}, \text { sand }, i}}{\mathrm{~d} t}=Q_{\mathrm{c}}+Q_{\mathrm{r}}+Q_{\text {coll }}
$$

Here $Q_{r}=Q_{\text {coll }}=0$, only the convective part is considered

$$
Q_{\mathrm{c}}=h A_{\mathrm{p}}\left(T_{\mathrm{f}}-T_{\mathrm{p}, \text { sand }, i}\right)
$$

where $A_{\mathrm{p}}=4 \pi r$ is the sand particle surface area, $h$ is the convective heat exchange coefficient, and $h=N u \lambda_{\mathrm{g}} / d_{\mathrm{p}}$. For simplicity, the Nusset number is calculated using ${ }^{33}$

$$
N u=2 \varepsilon_{\mathrm{g}}+0.69 \operatorname{Re}^{1 / 2} \operatorname{Pr}^{1 / 3}
$$

2.8. Gas-Phase Governing Equations. The governing equations for the gas phase are based on the Eulerian two-fluid model. The coupling between the gas-phase and solid-phase are through the source terms representing mass, momentum, and energy exchange. Table 8 lists the main governing equations for the gas phase.

In Table $8, \dot{R}_{\mathrm{g}, i}$ in eqs 27 and 28 is the net production rate of species $i$ arising from the gasification process, one part of which is read from the database gotten from the SPM and others come from the chemical reactions in the fluidized beds. $\beta_{\mathrm{g}-\mathrm{s}}$ in eq 29 is calculated using the Ergun equation, Wen and Yu equation. ${ }^{34} \Delta H_{\mathrm{rg}}$ in eq 30 is the homogeneous reaction heat, and $\dot{Q}_{\text {wood-gas }}$ is the heat flux from the biomass particles to the gas phase per unit volume, which is read from the database gotten from the SPM and summed up in a computational grid, $\dot{\mathrm{Q}}_{\text {wood-gas }}=\sum_{i=1}^{n} \dot{\mathrm{Q}}_{\text {wood }} / \mathrm{d} x \mathrm{~d} y d_{\mathrm{p}}$, while $\dot{\mathrm{Q}}_{\text {sand-gas }}$ is the heat flux from the sand particles to the gas phase, $\dot{Q}_{\text {sand-gas }}=\sum_{i=1}^{n} \dot{Q}_{c, i} / \mathrm{d} x$ $\mathrm{d} y d_{\mathrm{p}} . \mathbf{q}_{\mathrm{g}}$ is the heat flux in the gas phase due to the temperature gradient, $\mathbf{q}_{\mathrm{g}}=-k_{\mathrm{g}} \nabla T_{\mathrm{g}}$, where the gas heat conduction coefficient varies with temperature

$$
k_{\mathrm{g}}=2.518 \times 10^{-2} \sqrt{T_{\mathrm{g}} / 300.0}(\mathrm{~J} / \mathrm{s} \cdot \mathrm{m} \cdot \mathrm{k})
$$

Gas density varies with pressure and temperature 


$$
\rho_{\mathrm{g}}\left(T_{\mathrm{g}}\right)=\frac{p_{\mathrm{g}} \bar{M}}{R T_{\mathrm{g}}}=\frac{p_{\mathrm{g}}}{R T_{\mathrm{g}} \sum_{i=1}^{N} \frac{X_{\mathrm{g}, i}}{M_{\mathrm{g}, i}}}
$$

and the heat capacity is the mole-weighted average species heat capacity

$$
C_{\mathrm{g}}=\sum_{i=1}^{N} X_{\mathrm{g}, i} C_{\mathrm{gi}}
$$

and the heat capacity coefficients for gas species are listed in Table 9.

Table 9. Heat Capacity Coefficients for Gas Species

\begin{tabular}{ll} 
species & \multicolumn{1}{c}{ expression } \\
$\mathrm{O}_{2}$ & $C_{\mathrm{P}, \mathrm{O}_{2}}\left(T_{\mathrm{g}}\right)=\left(8.27+0.000258 T_{\mathrm{g}}-187700.0 / T_{\mathrm{g}}^{2}\right) / 32$ \\
$\mathrm{CO}$ & $C_{\mathrm{P}, \mathrm{CO}}\left(T_{\mathrm{g}}\right)=\left(6.6+0.0012 T_{\mathrm{g}}\right) / 28$ \\
$\mathrm{CO}_{2}$ & $\mathrm{C}_{\mathrm{P}, \mathrm{CO}_{2}}\left(T_{\mathrm{g}}\right)=\left(10.34+0.00274 T_{\mathrm{g}}-195500.00 / T_{\mathrm{g}}^{2}\right) / 44$ \\
$\mathrm{CH}_{4}$ & $C_{\mathrm{P}, \mathrm{CH}_{4}}\left(T_{\mathrm{g}}\right)=\left(5.34+0.0115 T_{\mathrm{g}}\right) / 16$ \\
$\mathrm{H}_{2} \mathrm{O}$ & $C_{\mathrm{P}, \mathrm{H}_{2} \mathrm{O}}\left(T_{\mathrm{g}}\right)=\left(8.22+0.00015 T_{\mathrm{g}}+0.00000134 T_{\mathrm{g}}^{2}\right) / 18$ \\
$\operatorname{tar}$ & $C_{\mathrm{P}, \mathrm{tar}_{\mathrm{g}}}\left(T_{\mathrm{g}}\right)=0.45$ \\
$\mathrm{H}_{2}$ & $\mathrm{C}_{\mathrm{P}, \mathrm{H}_{2}}\left(T_{\mathrm{g}}\right)=\left(6.62+0.00081 T_{\mathrm{g}}\right) / 2.02$ \\
$\mathrm{~N}_{2}$ & $\mathrm{C}_{\mathrm{P}, \mathrm{N}_{2}}\left(T_{\mathrm{g}}\right)=\left(6.5+0.001 T_{\mathrm{g}}\right) / 28.01$
\end{tabular}

\section{RESULTS AND DISCUSSIONS}

3.1. Results from the Single-Particle Model. To couple the database of the gasification information from a large-size wood particle, we need know the main factors affecting the gasification process. In this subsection, we study the influences of gas velocity and surrounding temperature on the gasification.

3.1.1. Influence of Gas Velocity on Gasification. For a gasification of a single beech wood particle, the surrounding gas is previously heated and the temperature is $T_{\text {Bulk }}=1023 \mathrm{~K}$ and the mass fractions of the hot input gas species are $Y_{\mathrm{g}, \mathrm{O}_{2}}=0.05$ and $Y_{\mathrm{g}, \mathrm{N}_{2}}=0.95$ respectively. We change the velocity of surrounding gas from $u_{g, \text { bulk }}=0.2(\mathrm{~m} / \mathrm{s})$ to $u_{\mathrm{g}, \text { bulk }}=0.8(\mathrm{~m} / \mathrm{s})$. Figure 3 shows the temporal variation of the gasification process at different velocities at the given surrounding conditions of temperature and components of input gas. Figure 3a shows the increase of the temperature at the particle surface, where the dotted horizontal line denotes the surrounding temperature $T_{\text {bulk }}=1023 \mathrm{~K}$. The temperature gradually increases from the initial $350 \mathrm{~K}$ to the surrounding temperature. Figure $3 \mathrm{~b}$ shows the heat flux at the particle surface. The negative value of $\dot{Q}$ means the gasification of a biomass particle is an endothermic process. Figure $3 c$ shows the mass variation of the biomass particle. The mass keeps almost a constant until the pyrolysis progress begins to consume the solid. Figure $3 \mathrm{~d}$ shows the sudden decrease of particle diameter at the end of the
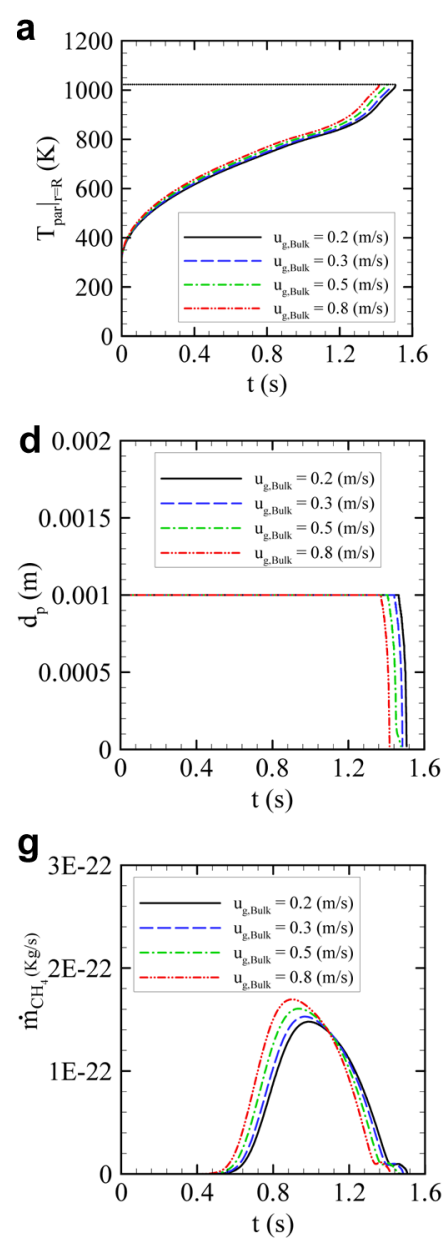
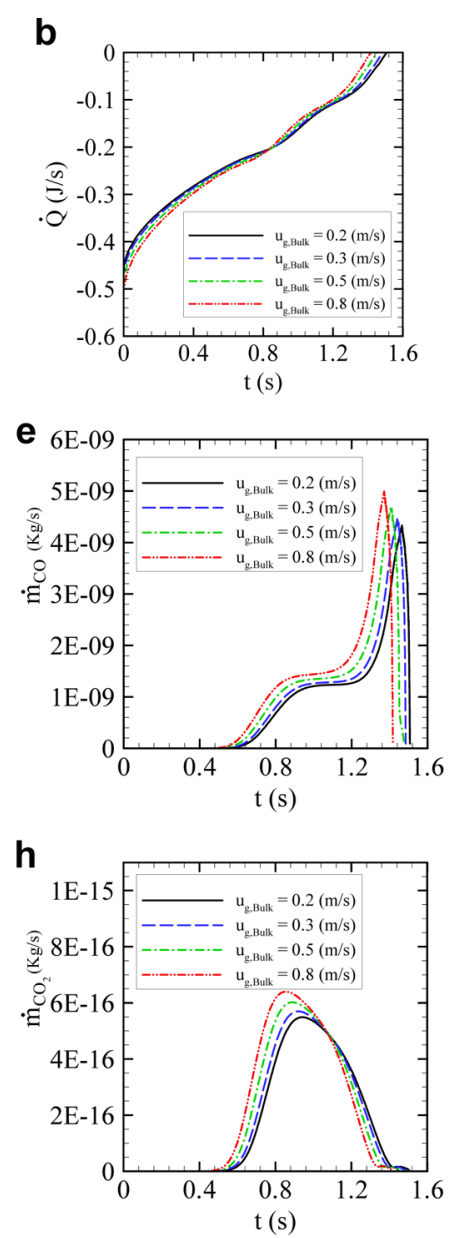
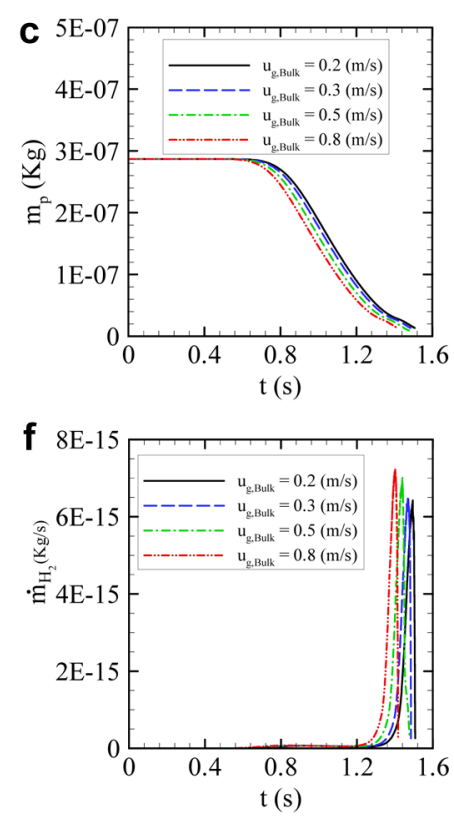

i

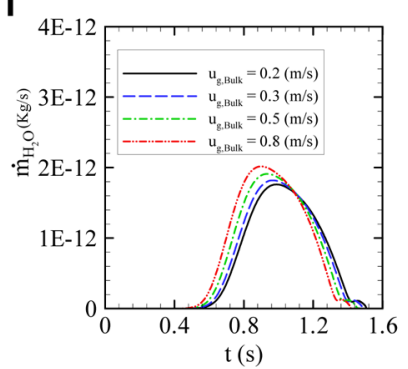

Figure 3. Influences of gas velocity on the gasification at temperature $T_{\text {bulk }}=1023 \mathrm{~K}$, input gas mass fractions $Y_{\mathrm{g}, \mathrm{O}_{2}}=0.05, Y_{\mathrm{g}, \mathrm{N}_{2}}=0.95$. When the velocity $u_{\mathrm{g}, \text { bulk }}$ increases by four times, from 0.2 to $0.8 \mathrm{~m} / \mathrm{s}$, the increased value of species mass flux is quite small, indicating that the influences of gas velocity on the gasification are not significant. 

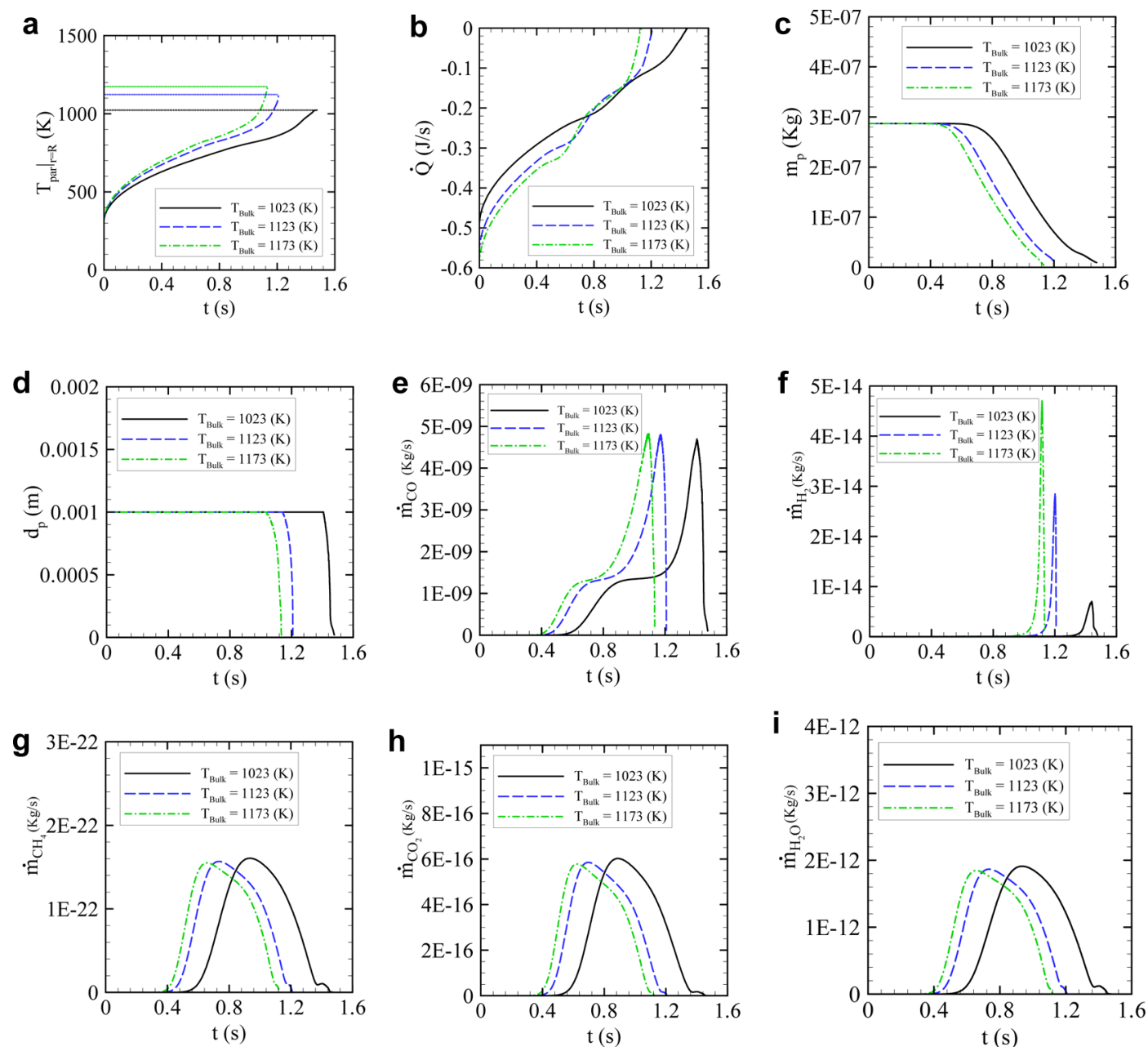

Figure 4. Influences of temperature on gasification, input gas mass fraction $Y_{\mathrm{g}, \mathrm{O}_{2}}=0.05, Y_{\mathrm{g}, \mathrm{N}_{2}}=0.95$, and the gas velocity $u_{\mathrm{g}, \mathrm{bulk}}=0.5 \mathrm{~m} / \mathrm{s}$. The gasification is sensitive to the surrounding temperature.

gasification because of heterogeneous reactions. Figure $3 \mathrm{e}-\mathrm{i}$ shows product rates of $\mathrm{CO}, \mathrm{H}_{2}, \mathrm{CH}_{4}, \mathrm{CO}_{2}$, and $\mathrm{H}_{2} \mathrm{O}$, respectively. We can observe that the main product is $\mathrm{CO}$, its product rate is several orders larger than those of the other products.

From Figure 3, one can see that with the increase of gas velocity at the same given temperature, the convective heat exchange efficiency increases, the heat flux from the gas phase into the wood particle is higher than that at lower velocity. The gasification process goes faster and the decrease of the wood diameter occurs earlier. However, although the velocity increases by four times, from 0.2 to $0.8 \mathrm{~m} / \mathrm{s}$, the increased value of species mass flux is quite small, indicating that the influences of gas velocity on the gasification are relatively nonsignificant.

3.1.2. Influence of Gas Temperature on Gasification. Figure 4 shows the variation of biomass particle gasification under different surrounding temperatures at the same given convective velocity $u_{\mathrm{g}, \text { bulk }}=0.5 \mathrm{~m} / \mathrm{s}$ and the mass fractions of hot input gas $Y_{\mathrm{g}, \mathrm{O}_{2}}=0.05, Y_{\mathrm{g}, \mathrm{N}_{2}}=0.95$. The biomass particle undergoes gasification under the surrounding temperatures of $T_{\text {bulk }}=1023,1123$, and $1173 \mathrm{~K}$, respectively. Figure4a shows that the temperature at the particle surface gradually approaches the surrounding temperatures during the gasification process. The dotted horizontal lines denote the surrounding temperatures. Figure $4 \mathrm{~b}$ shows the heat flux at the surface of the biomass particle, the higher temperature produces a large heat flux at the initial period of the gasification. The large heat flux enhances the gasification, as demonstrated by Figure $4 c-i$. From Figure $4 c-g$, one can observe that the gas temperature influences the gasification process significantly. Except the curve for $\mathrm{H}_{2}$ in Figure 4f, the shape of the curves almost keeps the same, however, all processes are shifted left with increasing temperatures. In Figure $4 \mathrm{f}$, it shows that higher temperature produces more $\mathrm{H}_{2}$. Thus the temperature is a dominating factor in biomass gasification and higher temperature significantly advances the gasification.

To save computational cost, we do not need to directly couple the SPM with the Eulerian continuum model for the fluidized bed by simultaneously solving the two kinds of models. Instead, we can use a database of the gasification by solving the SPM at a statistically steady temperature. In practice, gasification is an endothermic process, the temperatures of biomass particles and the gas phase is intensively coupled in the fluidized bed. To mimic a similar steady environment under which the single biomass particle gasification occurs, we need a strong heat source in the fluidized bed to maintain the gas temperature steady during the gasification process. In this study, we use hot sand particles as heat energy carrier to supply the energy to gas phase and 
wood particles, thus we simulate the fluidization of a mixture of hot sand particles and wood particles in the next subsection.

3.2. Gasification of Biomass Particles in a Bubbling Fluidized Bed. In this subsection, we couple the database from the SPM under conditions that gas velocity is $u_{\mathrm{g}, \text { bulk }}=0.4762 \mathrm{~m} / \mathrm{s}$, the mass fractions of input gas are $Y_{\mathrm{g}, \mathrm{O}_{2}}=$ $0.05, Y_{\mathrm{g}, \mathrm{N}_{2}}=0.95$, and the surrounding temperature is $T_{\text {bulk }}=1123 \mathrm{~K}$. To keep the surrounding temperature nearly a constant, small sand particles are used as thermal carrier. The density of the sand particle is $2500 \mathrm{~kg} / \mathrm{m}^{3}$, and the particle diameter is $d_{\mathrm{p}, \mathrm{s}}=0.6 \times 10^{-3} \mathrm{~m}$. The fluidized bed is a two-dimensional domain, its size is $0.05 \mathrm{~m} \times 0.2 \mathrm{~m}$, the third direction has a width of a particle diameter and slip conditions for gas and solid particles are used. The number of sand particle is 2000. One biomass particle goes into the fluidized bed at an interval of 50 time steps and the maximum number for biomass particles is 50 . The initial biomass particle diameter is $0.001 \mathrm{~m}$.

The minimum fluidization velocity for the sand particles can be estimated by ${ }^{35}$

$$
\begin{aligned}
& \frac{1.75}{\varepsilon_{\mathrm{g}, \mathrm{mf}}}\left(\frac{d_{\mathrm{p}, \mathrm{s}} u_{\mathrm{g}, \mathrm{mf}} \rho_{\mathrm{g}}}{\mu_{\mathrm{g}}}\right)^{2}+\frac{150\left(1-\varepsilon_{\mathrm{g}, \mathrm{mf}}\right)}{\varepsilon_{\mathrm{g}, \mathrm{mf}}{ }^{3}} \frac{d_{\mathrm{p}, \mathrm{s}} u_{\mathrm{g}, \mathrm{mf}} \rho_{\mathrm{g}}}{\mu_{\mathrm{g}}} \\
& =\frac{\left.d_{\mathrm{p}, \mathrm{s}} \rho_{\mathrm{g}} \rho_{\mathrm{p}}-\rho_{\mathrm{g}}\right) g}{\mu_{\mathrm{g}}^{2}}
\end{aligned}
$$

where $\varepsilon_{\mathrm{g}, \mathrm{mf}}$ is the bed voidage at minimum fluidization velocity and $\varepsilon_{\mathrm{g} \text {,mf }}=0.5, \rho_{g}=0.3 \mathrm{~kg} / \mathrm{m}^{3}, \mu_{g}=44.88 \times 10^{-6} \mathrm{~Pa} \cdot \mathrm{s}$. Then, $u_{\mathrm{g}, \mathrm{mf}}=0.07 \mathrm{~m} / \mathrm{s}$. In an experiment carried out by Zhang et al., ${ }^{36}$ the similar sand particles are fluidized by air and the minimum fluidization velocity is about $0.207 \mathrm{~m} / \mathrm{s}$. The gas velocity $u_{\mathrm{g}, \text { bulk }}$ used in the simulation is large enough to fluidize the sand particles.

The fluidization, mixing and entrainment of biomass particles and inert sand particles are very important for the gasification process. More details please refer to ref 37, where the experimental multiphase flows in the fluidization of biomass particles are reviewed. Because of the large differences in the properties of the biomass-sand mixture, it is regarded as a critical factor affecting the mixing and entrainment behavior. Figure 5 shows that the position distribution of particles and

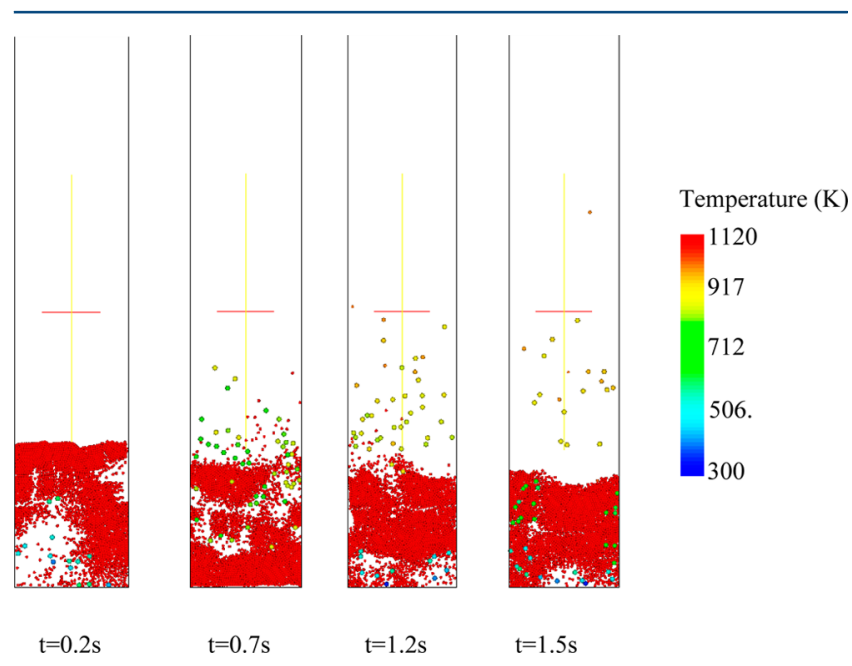

Figure 5. Position distribution of particles and heterogeneous structures in the fluidized bed. their temperatures at different times. We can observe that the sand particles (in red) nonuniformly distribute in the fluidized beds and heterogeneous structures appears with bubbles devoid of particles and dense regions full of particles. The hot sand particles serve as heat carrier. The blue ones are cool wood particles and go into the reactor through the bottom. The wood particle temperature increases during they stay in the reactor as the color becomes green, further yellow and red. It is shown that the wood particles have been heated by the surrounding gas and collision with hot sand particles before been entrained to the upper part of the bed due to the density differences.

Figure 6 shows the transient flow velocity field of gas phase at different times. We can observe the distribution of gas

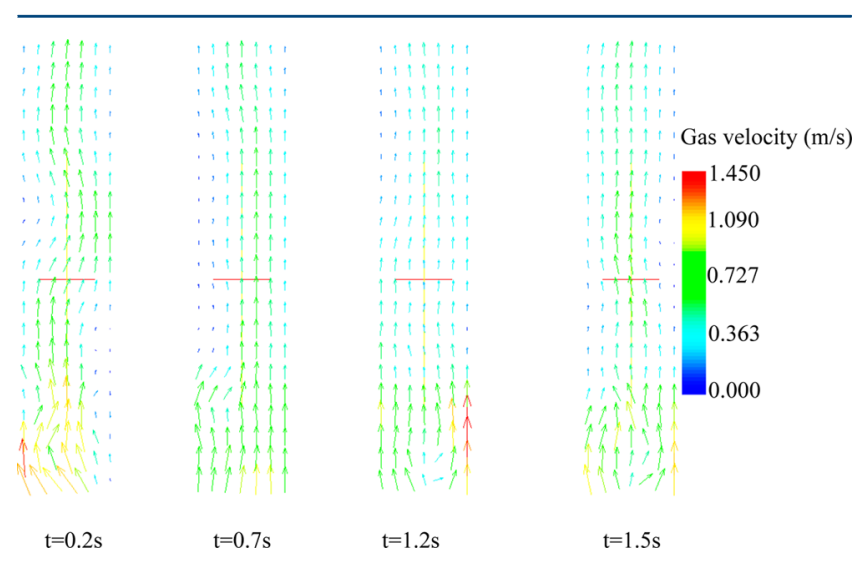

Figure 6. Transient distribution of gas phase flow field.

velocity is also nonuniform due to the strong coupling between the solid phase and gas phase. The gas tends to go through the channel in the void regions of the bed, manifesting the typical characteristics of bubbling fluidized bed. Above the dense solid-gas region, the gas velocity recovers behaviors a single phase flow in bed, with large velocity in the core region and smaller and smaller velocities toward the side walls.

At the outlet, the main species of the gas phase are $\mathrm{N}_{2}$ and CO. The time-averaged mass fractions of gas phase are $Y_{\mathrm{g}, \mathrm{N}_{2}}=0.987$ and $Y_{\mathrm{g}, \mathrm{CO}}=0.0125$, respectively. Other species such as $\mathrm{H}_{2}$ and $\mathrm{CH}_{4}$ are very tiny and have no practical significances; the reason is that the amount of wood particles introduced in the bed is too small. We will improve the amount of wood particles or the ratio of wood to sand particles in future study.

\section{CONCLUSIONS}

One of the challenges posed by the numerical simulation of biomass gasification is its multiscale coupling nature that spans several orders of magnitude in space and time. To reduce the computational cost, a multiscale coupling framework between the SPM based on detailed reaction mechanisms and the DEMcontinuum model for the fluidized bed is proposed. The coupling framework is based on the observations on the solution of the SPM that the dominating factor controlling gasification is the temperature. Although the gas velocity changes position by position in the fluidized bed, we can loosely couple the solution of the SPM with the DEMcontinuum if we can maintain the similar temperature in the fluidized bed. For this purpose, we use sand particle as thermal carrier to keeps the surrounding temperature statistically stable. Using the proposed method, we get the particle and flow field, temperature distribution and gas products such as $\mathrm{CO}$ from the 
wood particles in a small scale bubbling fluidized bed. The key point of the loose coupling method is to get the timedependent solutions of the SPM at the boundary to coupling them with a conventional Eulerian-Lagrangian model for the fluidized bed.

The particle size of $1 \mathrm{~mm}$ is taken as an example in this paper. We can get the solution of a single large-size particle of any given diameter, and then couple it with the conventional CFD simulation of fluidized bed in practical application.

Further study should be carried out to numerical simulation of a pilot-scale fluidized and validate the numerical results with experiment results. For this purpose, the coupling between an Eulerian-Eulerian model for gas and sand phases and the DEM for biomass particles needs to be developed, since tracking the huge number of sand particles consumes a large fraction of computational time.

\section{AUTHOR INFORMATION}

\section{Corresponding Author}

*Tel: 86-10-82543928. Fax: 86-10-82543977. E-mail: gdjin@ lnm.imech.ac.cn.

\section{Notes}

The authors declare no competing financial interest.

\section{ACKNOWLEDGMENTS}

The fellowship from the Max-Planck Society is gratefully acknowledged. This work is supported by NSFC under Nos. 11072247and NSAF under No.U1230126. The author would like to thank Professor F. Behrendt and Dr. M. Oevermann at the Institute of Energy Engineering Berlin University of Technology for the instructive discussions and many helps in life during the research stay at TU, Berlin. The author would like to thank Dr. Birgit Wilmes who provided the database of the Single Particle Model. The author also got helps from the colleagues, Y. F. Kuo, M. Bogdanic, N. Zobel, and Y. Neubauer at the institute. The author would like thank the anonymous referees for their very constructive and insightful suggestions and comments on the original manuscript.

\section{ABBREVIATIONS}

CFD = computational fluid dynamics

DEM = discrete element method

EMMS = energy-minimization multi-scale method

MFIX = multiphase flow with interphase exchanges

SPM = single particle model

tpCWM = time parallel compound wavelet matrix

TFM = two-fluid model

\section{Nomenclature}

$C=$ molar concentration $\left(\mathrm{mol} / \mathrm{m}^{3}\right)$

$\mathrm{C}_{\mathrm{g}}=$ mean heat capacity of gas phase in fluidized bed $(\mathrm{J} / \mathrm{kg} / \mathrm{K})$

$C_{\mathrm{g} i}=$ specific heat capacity of gas species in fluidized bed $(\mathrm{J} / \mathrm{kg} / \mathrm{K})$

$C_{\mathrm{pg}}, C_{\mathrm{pl}}, C_{\mathrm{ps}}=$ specific heat capacity of gas phase, liquid phase, and solid phase $(\mathrm{J} / \mathrm{kg} / \mathrm{K})$

$C_{\mathrm{pg}, i}=$ specific heat capacity of gas species $i(\mathrm{~J} / \mathrm{kg} / \mathrm{K})$

$d_{\mathrm{p}, \mathrm{s}}=$ sand particle diameter $(\mathrm{m})$

$D_{\mathrm{b}}=$ diffusion coefficient $\left(\mathrm{m}^{2} / \mathrm{s}\right)$

$D_{\text {eff }, i}=$ effective diffusion coefficient $\left(\mathrm{m}^{2} / \mathrm{s}\right)$

$D_{\mathrm{g}, i}=$ molecular diffusion coefficient corresponding to the different gas species, $D_{\mathrm{g}, i}=0.165 \times 10^{-4} \mathrm{~m}^{2} \mathrm{~s}^{-1}$
$E_{i}=$ activation energy in individual primary pyrolysis $(\mathrm{kJ} / \mathrm{mol})$

$\mathbf{F}_{\mathrm{d}, i}=$ particle drag force $\left(\mathrm{kg} \cdot \mathrm{m} / \mathrm{s}^{2}\right)$

$\mathbf{F}_{\mathrm{c}, i}=$ particle contact force during collision $\left(\mathrm{kg} \cdot \mathrm{m} / \mathrm{s}^{2}\right)$

$\mathbf{g}=$ gravitation acceleration $\left(\mathrm{m} / \mathrm{s}^{2}\right)$

$k_{0}=$ rate constant $(1 / \mathrm{s})$

$k_{0 i}=$ individual primary pyrolysis rate constant $(1 / \mathrm{s})$

$K_{\mathrm{g}}, K_{1}=$ permeability for gas phase and liquid $\left(\mathrm{m}^{2}\right)$

$K_{\mathrm{e}}=$ equilibrium constant

$M_{\mathrm{H}_{2} \mathrm{O}}=$ molar mass of water $(\mathrm{kg} / \mathrm{mol})$

$M_{\mathrm{g}, i}=$ mean molar mass of gas species $i(\mathrm{~kg} / \mathrm{mol})$

$\bar{M}=$ mean molar mass of gas phase $(\mathrm{kg} / \mathrm{mol})$

$m_{\mathrm{p}, i}=$ mass of a particle

$p=$ pressure of the gas phase in fluidized bed $(\mathrm{Pa})$

$p_{\mathrm{pg}}=$ pressure of gas phase in the porous particle $(\mathrm{Pa})$

$p_{\mathrm{pg}}=$ pressure in gas phase $(\mathrm{Pa})$

$p_{c}=$ capillary pressure in the interface between gas and liquid (Pa)

$p_{\mathrm{p}, \mathrm{H}_{2} \mathrm{O}}=$ equilibrium pressure of water in the particle $(\mathrm{Pa})$

$Q=$ loss of heat due to evaporation and chemical reaction

$\left(\mathrm{J} / \mathrm{m}^{3} / \mathrm{s}\right)$

$\dot{r}_{\text {dry }}=$ drying rate $\left(\mathrm{mol} / \mathrm{m}^{3} / \mathrm{s}\right)$

$\dot{r}_{\text {pyro }, i}=$ individual primary pyrolysis rate $\left(\mathrm{kg} / \mathrm{m}^{3} / \mathrm{s}\right)$

$\dot{r}_{i, \text { crack }}=$ individual secondary pyrolysis rate $(\mathrm{kg} / \mathrm{kg} / \mathrm{s})$

$\dot{r}_{\mathrm{s} \rightarrow \mathrm{g}}=$ mass product rate from solid to gas phase $\left(\mathrm{mol} / \mathrm{m}^{3} / \mathrm{s}\right)$

$\dot{r}_{1-\mathrm{g}}=$ mass product rate from liquid to gas phase $\left(\mathrm{mol} / \mathrm{m}^{3} / \mathrm{s}\right)$

$\dot{r}_{\mathrm{g} \rightarrow \mathrm{g}, i}=$ gas species product rate from tar and from homogeneous reactions $\left(\mathrm{mol} / \mathrm{m}^{3} / \mathrm{s}\right)$

$\dot{r}_{\mathrm{s} \rightarrow \mathrm{g}, i}=$ gas species product rate from wood particle through primary pypolysis and heterogeneous reactions $\left(\mathrm{mol} / \mathrm{m}^{3} / \mathrm{s}\right)$

$\dot{r}_{1 \rightarrow \mathrm{g}, i}=$ gas species product rate from liquid phase $\left(\mathrm{mol} / \mathrm{m}^{3} / \mathrm{s}\right)$

$\dot{r}_{s \rightarrow \text { s,char }}=$ char product rate from wood $\left(\mathrm{kg} / \mathrm{m}^{3} / \mathrm{s}\right)$

$\dot{R}_{\mathrm{g}, i}=$ net production rate of species $i\left(\mathrm{~kg} / \mathrm{m}^{3} / \mathrm{s}\right)$

$R=$ ideal gas constant and $R=8.314(\mathrm{~J} / \mathrm{mol} / \mathrm{K})$

$T_{\text {par }}=$ local temperature in particle $(\mathrm{K})$

$T_{\mathrm{p}, \text { sand }}=$ temperature of sand particle $(\mathrm{K})$

$T_{\mathrm{g}}=$ local temperature of gas phase $(\mathrm{K})$

$\mathbf{T}_{c, i}=$ torque caused by the tangential component of contacting force $\left(\mathrm{kg} \cdot \mathrm{m}^{2} / \mathrm{s}^{2}\right)$

$\mathbf{u}_{\mathrm{g}}=$ gas velocity in the fluidized bed $(\mathrm{m} / \mathrm{s})$

$X_{\mathrm{pg}, i}=$ molar fraction of gas species in gas phase in the wood particle

$X_{\mathrm{g}, i}=$ molar fraction of gas species in gas phase in the fluidized bed

$Y_{\mathrm{ps}, i}=$ mass fraction of components of pyrolysis products in solid state in wood particle

$Y_{\mathrm{pg}, \mathrm{tar}}=$ mass fraction of tar in gas phase in the wood particle

$Y_{\mathrm{pg}, i}=$ mass fraction of gas species in gas phase in the wood particle

$Y_{\mathrm{g}, i}=$ local mass fraction of species

$w_{\mathrm{g}, \mathrm{H}_{2} \mathrm{O}}=$ mass fraction of vapor in the gas phase

$\alpha_{i}=$ relative stoichiometric coefficients

$\beta_{\mathrm{g}-\mathrm{s}}=\mathrm{drag}$ force coefficient on particles in unit volume $\left(\mathrm{kg} / \mathrm{s} / \mathrm{m}^{3}\right)$

$\varepsilon_{\mathrm{g}}=$ gas volume fraction in the fluidized bed

$\lambda_{\text {eff }}=$ heat conductivity coefficient $\left(\mathrm{w} / \mathrm{m}^{2} \mathrm{k}\right)$

$\mu_{\mathrm{g}} \mu_{1}=$ dynamic viscosity of gas phase and liquid phase $(\mathrm{kg} / \mathrm{m} / \mathrm{s})$

$\rho_{\text {pg }}=$ gas density in the porous particle $\left(\mathrm{kg} / \mathrm{m}^{3}\right)$

$\rho_{\mathrm{ps}}=$ density of the solid phase in porous wood particle $\left(\mathrm{kg} / \mathrm{m}^{3}\right)$

$\rho_{\mathrm{g}}=$ gas density in the fluidized bed $\left(\mathrm{kg} / \mathrm{m}^{3}\right)$

$\overline{\bar{\tau}}_{\mathrm{g}}=$ stress tensor $(\mathrm{Pa})$ 
$\varphi_{\mathrm{pg}}=$ volume fraction of gas phase in the porous particle

$\varphi_{\mathrm{ps}}=$ volume fraction of solid part in porous wood particle

\section{REFERENCES}

(1) Kirkels, A. F.; Verbong, G. P. J. Biomass Gasification: Still Promising? A 30-Year Global Overview. Renewable Sustainable Energy Rev. 2011, 15, 471-481.

(2) Pereira, E. G.; Silva, J. N; Oliveira, J. L.; Machado, C. S. Sustainable Energy: A Review of Gasification Technologies. Renewable Sustainable Energy Rev. 2012, 16, 4753-4762.

(3) Wilmes, B. Modellierung und Simulation der Vergasung eines Holzpartikels unter Verwendung Detaillierter Reaktionsmechanismen. Ph.D.Thesis, Technischen Universitaet Berlin, 2007.

(4) Miller, R. S.; Bellan, J. A Generalized Biomass Pyrolysis Model Based on Superimposed Cellulose, Hemicellose and Lignin Kinetics. Combust. Sci. Technol. 1997, 126, 97-137.

(5) Oevermann, M.; Gerber, S.; Behrendt, F. Euer-Lagrange/DEM Simulation of Wood Gasification in a Bubbling Fluidized Bed Reactor. Particuology 2009, 7, 307-316.

(6) Basu, P. Biomass Gasification and Pyrolysis Practical Design and Theory; Academic Press: Amsterdam, 2010.

(7) Okekunle, P. O; Watanabe, H.; Pattanotai, T.; Okazaki, K. Effect of Biomass Size and Aspect Ratio on Intra-Particle Tar Decomposition during Wood Cylinder Pyrolysis. J. Therm. Sci. Technol. 2012, 7 (1), $1-15$.

(8) Zhang, D.; VanderHeyden, W. B. The Effects of Mesoscale Structures on the Macroscopic Momentum Equations for Two-Phase Flows. Int. J. Multiphase Flow 2002, 28, 805-822.

(9) Li, J. H.; Kwauk, M. Particle-Fluid Two-Phase Flow-the EnergyMinimization Multi-Scale Method; Metallurgical Industry Press: Beijing, 1994.

(10) Yang, N.; Wang, W.; Ge, W.; Li, J. H. CFD Simulation of Concurrent up Gas-Solid Flow in Circulating Fluidized Beds with Structure-Dependent Drag Coefficient. Chem. Eng. J. 2003, 96, 71-80.

(11) Yang, N. A Multi-Scale Framework for CFD Modelling of MultiPhase Complex Systems Based on the EMMS Approach. Prog. Comp. Fluid Dyn. 2012, 12, 220-229.

(12) Wang, W.; Li, J. Simulation of Gas-Solid Two-Phase Flow by a Multi-Scale CFD Approach-extension of the EMMS Model to the Sub-Grid Level. Chem. Eng. Sci. 2007, 62, 208-231.

(13) Wang, J.; Ge, W.; Li, J. Eulerian Simulation of Heterogeneous Gas-Solid Flows in CFB Risers: EMMS-Based Sub-Grid Scale Model with a Revised Cluster Description. Chem. Eng. Sci. 2008, 63, 15531571.

(14) Pannala, S.; Simunovic, S.; Frantziskonis, G. Multiscale/ Multiphysics Modeling of Biomass Thermochemical Processes. in Computational Modeling in Lignocellulosic Biofuel Production; Nimlos, M. R., Crowley, M. F., Ed.; ACS Symposium Series 1052; American Chemical Society: Washington, DC, 2010; Vol. 1052, 245-271.

(15) He, G.-W.; Xia, M. F.; Ke, F. J.; Bai, Y. L. Multi-Scale Coupling: Challenges and Opportunities. Prog. Nat. Sci. 2004, 14 (6), 463-466.

(16) Di Blasi, C. Modeling Chemical and Physical Processes of Wood and Biomass Pryolysis. Prog. Energy Combust. Sci. 2008, 34, 47-90.

(17) Anca-Couce, A.; Zobel, N. Numerical Analysis of a Biomass Pyrolysis Particle Model: Solution Method Optimized for the Coupling to Reactor Model. Fuel 2012, 97, 80-88.

(18) Anca-Couce, A.; Zobel, N.; Jakobsen, H. A. Multi-Scale Modeling of Fixed-Bed Thermo-Chemical Processes of Biomass with the Representative Particle Model: Application to Pyrolysis. Fuel 2013, 103, 773-782.

(19) Syamlal, M.; Rogers, W.; O’Brien, T. J. MFIX Documentation Theory Guide, Technical Note; Report No. DOE/METC-94/ 1004(DE94000087),1993.

(20) Wurzenberger, J. C.; Wallner, S.; Raupenstrauch, H.; Khinst, J. G. Thermal Conversion of Biomass: Comprehensive Reactor and Particle Modeling. AIChE J. 2002, 45, 2398-2411.

(21) Seebauer, V. Experimentelle Untersuchungen zur Pyrolyse von Kohle und Holz, Ph.D.Thesis, Technischen Universitaet Graz, 1999.
(22) Boroson, M. L.; Howard, J. Product Yields and Kinetics from the Vapour Phase Cracking of Wood Pyrolysis Tars. AIChE J. 1989, $35,120-128$.

(23) Yoon, H.; Wei, J.; Denn, M. M. A Model for Moving Bed Coal Gasification Reactors. AIChE J. 1978, 24, 885-903.

(24) Cooper, J.; Hallet, W. L. A Numerical Model for Packed-Bed Combustion of Char Particles. Chem. Eng. Sci. 2000, 55, 4451-4460.

(25) de Souza-Santos, M. L. Comprehensive Modelling and Simulation of Fluidized Bed Boilers and Gasifiers. Fuel 1989, 68, $1507-1521$.

(26) Di Blasi, C. Modeling Wood Gasification in a Countercurrent Fixed-Bed Reactor. AIChE J. 2004, 50 (9), 2306-2319.

(27) Rajan, R. R; Wen, C. Y. A Comprehensive Model for Fluidized Bed Coal Combustors. AIChE J. 1980, 26, 642-655.

(28) Di Blasi, C.; Buonanno, C. F.; Branca, C. Reactivities of Some Biomass Chars in Air. Carbon 1999, 37, 1227-1238.

(29) Biggs, M. J.; Agarwal, P. K. The $\mathrm{CO} / \mathrm{CO}_{2}$ Product Ratio for a Porous Char Particle within an Incipiently Fluidized Bed: A Numerical Study. Chem. Eng. Sci. 1997, 52, 941-952.

(30) Mühlen, H.-J.; van Heek, K. H.; Jüngen, H. Kinetic Studies of Steam Gasification of Char in the Presence of $\mathrm{H}_{2}, \mathrm{CO}_{2}$ and CO. Fuel 1985, 64, 944-949.

(31) Cundall, P. A.; Strack, O. D. L. A Discrete Numerical Model for Granular Assemblies. Geotechnique 1979, 29 (1), 47-65.

(32) Tsuji, Y.; Tanaka, T.; Ishida, T. Lagrangian Simulation of Plug Flows of Cohesionless Particles in a Horizontal Pipe. Powder Technol. 1992, 71, 239-250.

(33) Zhou, H. S.; Flamant, G.; Gauthier, D. DES Simulation of Coal Combustion in a Bubbling Fluidized Bed Part 2 Coal Combustion at the Particle Level. Chem. Eng. Sci. 2004, 59, 4205-4215.

(34) Didaspow, D. Multiphase Flow and Fluidization: Continuum and Kinetic Theory Description; Academic Press: Boston, 1994.

(35) Kunii, D.; Levenspiel, O. Fluidization Engineering, Wiley: New York, 1969.

(36) Zhang, Y.; Jin, B. S.; Zhong, W. Q. Fluidization, Mixing and Segregation of a Biomass-Sand Mixture in a Fluidized Bed. Int. J. Chem. Reactor Eng. 2008, 6, 1-29.

(37) Cui, H. P.; Grace, J. R. Fluidization of Biomass Particles: A Review of Experimental Multiphase Flow Aspects. Chem. Eng. Sci. 2007, 62, 45-55. 